\title{
Targeting Melanoma Sites in Vivo can Induce Complete Tumor Ablation and Prolong Patient Survival: An Exploratory Study
}

\section{E. George Elias ${ }^{1 *}$ and Bhuvnesh K Sharma ${ }^{2}$}

${ }^{1}$ University of Maryland at St. Joseph Medical Center The cancer Institute, USA ${ }^{2}$ BIOCARE MEDICAL, LLC, USA

\begin{abstract}
Dermal and subdermal metastases as well as primary invasive melanoma allow an excellent opportunity to study the effects of intralesional therapy. The therapy consisted of weekly intralesional administration of nontoxic doses of granulocyte-macrophage colony stimulating factor at 500 microgram, and in case of failure to establish complete tumor response at the injection sites in 4-6 weeks; weekly intralesional interleukin-2 at 18 million international units was substituted. The results revealed complete response in patients with multiple small in transit metastases ranging in size from few millimeters to one centimeter $(n=4)$ for over 31-48 months, but not in any of the large sclerotic lesions of 2 centimeter or more $(n=3)$. Complete responses were elicited for 6 months in one of two patients with distant metastases who had palpable subdermal tumors treated with granulacyte-macrophage colony stimulating factor. A patient with primary cutaneous melanoma with a satellite lesion and and a large regional lymph node metastasis received both cytokines in the skin sites, one week prior to surgery, had complete tumor necrosis, intense immune response at the injection sites and at the regional lymph nodes, with over 36 months disease free survival. This could be an affective new approach to tumor-specific adjuvant immunotherapy.
\end{abstract}

Keywords: Metastases; Adjuvant immunotherapy; Interleukin-2 (IL-2); Granulocyte-Macrophage Colony Stimulating Factor (GM-CSF)

\section{Introduction}

Satellitosis and intransit metastases are not uncommon complications in patients with cutaneous melanoma, and various therapeutic approaches have been attempted in their management, depending on the site and extent of the disease. These included repeated local excisions, hyperthermic isolated limb perfusion, limb infusion, laser therapy, intralesional (intratumoral) injections of a variety of chemotherapeutic and bio-therapeutic agents, gene therapy, and as a final resort radiation therapy and systemic therapy. Each of these approaches was met with limited success, and as a result, there has been no standard treatment for these patients. Furthermore, adjuvant therapy in high risk patients with primary melanoma is being administered systemically after complete resection of the disease to prevent or at least delay recurrence. As melanoma is considered to be an immunogenic tumor, but relatively chemotherapy resistant, various postoperative adjuvant vaccines and bio-therapeutic approaches were tried, and again resulted in limited benefits.

In the meantime, intralesional administration of two cytokines in intransit metastatic melanoma, each gave promising results based on clinical and biological findings. Clinically, intralesional administration of granulocyte-macrophage colony stimulating factor (GM-CSF, Leukine, Genzyme Corporation) at 400-500 microgram ( $\mu \mathrm{g}) /$ day for 4-5 consecutive days and repeated every 21-28 days gave high response rates, some were of long duration [1,2]. Similarly, intralesional administration of interleukin-2 (IL-2, Proleukin, Prometheus Laboratories) at doses ranging from 0.6-6.0 million international unit (IU) two to three times/week or with escalating doses gave durable responses, but with grade I/II toxicity [3-5]. However, these two cytokines were not used consecutively. Biologically, these two cytokines have different mechanisms of action that may complement one another. GM-CSF is a multifunctional molecule that can mainly increase the number and activation of autologous dendritic cells (DCs) and increases the expression of IL-2 receptors on some subsets of T cells [6-7]. It has also been well established that IL-2 administration stimulates $\mathrm{T}$ cells, augment natural killer (NK) cells proliferation and function and activates cytotoxic T cells [8]. More importantly, there was no evidence that intralesional administration of either agent induced disease dissemination.

This exploratory study was undertaken to evaluate the local and systemic response to a standard nontoxic dose of intralesional GMCSF at $500 \mu \mathrm{g}$ once per week on dermal and subdermal melanoma, regardless to the extent of their disease. In case of any significant toxicity or failure to establish complete tumor response (CR) at the injection sites within 4-6 weeks, intralesional IL-2 was substituted at 18 million IU weekly.

\section{Material and Methods}

This exploratory study was approved by the Human Experimentation to evaluate the local and systemic effects of weekly intralesional administration of GM-CSF or IL-2 in patients with dermal and subdermalmelanoma, regardless to the extent of the disease or previous therapy. The treated tumor sites had pathological documentation of melanoma.

Prior to initiating the therapy, the patient underwent complete work up which included complete history and physical examination, complete blood count, white cell count (WBC) with cell differentiation, serum chemistries with hepatic and renal profile and lactic

*Corresponding author: E. George Elias, MD, PhD: 1214 Merediths Ford Road, Towson Maryland 21286-1320, USA, Tel: 410-296 1344; E-mail: egelias1@comcast.net

Received May 07, 2013; Accepted May 30, 2013; Published June 03, 2013

Citation: Elias EG, Sharma BK (2013) Targeting Melanoma Sites in Vivo can Induce Complete Tumor Ablation and Prolong Patient Survival: An Exploratory Study. J Cancer Sci Ther 5: 244-248. doi:10.4172/1948-5956.1000212

Copyright: @ 2013 Elias EG, et al. This is an open-access article distributed under the terms of the Creative Commons Attribution License, which permits unrestricted use, distribution, and reproduction in any medium, provided the original author and source are credited. 
dehydrogenase (LDH). Positron emission tomography with computed tomography (PET/CT) was performed to identify the extent of the disease. The study was then thoroughly explained to the patient and after signing the consent form, dermal lesions were photographed, and the palpable subcutaneous lesions had their sites marked on the skin with none washable permanent marker. Intralesional therapy was then initiated. GM-CSF was administered initially at $500 \mu \mathrm{g}$ once per week. In case of significant toxicity or failure to establish CR in 4-6 weeks at the injection sites, depending on the extent of the disease, intralesional IL-2 was substituted at 18 million IU weekly for the same length of time to obtain CR at the injection sites, otherwise considered failure. Complete tumor response was characterized by complete disappearance of the tumor clinically at the injection sites without local recurrence for 6 months, and confirmed pathologically by repeated biopsy of some of the lesions in 6-8 weeks after cessation of therapy. Anything less than complete response was considered failure.

During therapy, an attempt was made to completely fill each lesion or group of lesions with the agent, and to as many lesions per setting but not to exceed the weekly dosage. Large coalesced scarred skin lesions were injected mostly peri-lesional because of the inability to completely infiltrate the tumor site. During either cytokine administration, the patient was evaluated weekly and had complete physical examination with all blood tests repeated every two weeks. Patients who failed to respond to either cytokine therapy were taken off the study and treated with other therapeutic modalities. On the other hand, when complete tumor response was established, therapy was discontinued and the patient was closely observed. The responders had their physical examination and laboratory tests continued every two weeks for two months, then every three months during the first two years of followup. PET/CT scans were repeated every six months, unless otherwise indicated. On the other hand, patients with distant metastases had their scans repeated every two months.

Ten consecutives patients were studied and completed over 30 month of follow up. There were 6 men and 4 women. Their ages ranged from 39-79 with a median of 52. Four patients had regional lympha denectomy performed for metastatic melanoma at the time of the initial diagnoses and one had elective lymphadenectomy and all the lymph nodes (LNs) were negative for metastases. Another four patients had no metastases to the sentinel LNs initially and had no palpable lymph nodes at the time of their enrollment in the study. The 10th patient presented with primary melanoma of the skin of the left forearm with a satellite lesion and clinically enlarged $\mathrm{LN}$ in the left axilla and was treated preoperatively.

The study patients consisted of four patients (\# 1-4), table 1, with in transit metastases, mostly in the subcutaneous tissues with three of them having 26 lesions, each measuring from few millimeters to one centimeter and patient \#2 had numerous small in transit metastases all around the skin graft of the scalp that were too many to count and estimated to be over 100 lesions (Figure 1A). They were all previously treated for their intransit metastases by various methods including two who failed hyperthermic isolated limb perfusion, table 1 . Two patients $(\# 1,3)$ had initially failed a 2 -year program of postoperative systemic adjuvant therapy that consisted of subcutaneous administration of GM-CSF: $125 \mu \mathrm{g} / \mathrm{m}^{2} /$ day for 14 consecutive days followed by IL-2: 9 million $\mathrm{IU} / \mathrm{m}^{2} /$ day for 4 days. The treatment was repeated every month for two years. One patient developed in transit metastases 3 months after completing the 2years of therapy, and the other developed in transit metastases while receiving the adjuvant systemic therapy. Another three patients (\# 5-7) had multiple large sclerotic and matted skin lesions, after repeated surgical excisions and radiation therapy with each lesion measuring over $2 \mathrm{~cm}$. Both groups had no evidence of regional or distant metastases. Another patient (\# 8) was newly diagnosed with primary cutaneous melanoma on the dorsal aspect of the left forearm of $1.98 \mathrm{~mm}$ depth of invasion by shave biopsy with tumor present at the margins of the biopsy. Pathologically, the primary lesion was not ulcerated but had seven mitoses $/ \mathrm{mm}^{2}$, and a $2 \mathrm{~mm}$ satellite located about $1 \mathrm{~cm}$ from the primary site. This patient had also an enlarged left axillary LN, i.e., had stage III C disease, but remained to be a surgical candidate with guarded prognosis. Due to the small size of the biopsy sites of the primary and the satellite, and because ethically the patient had to undergo surgical excision of the

\begin{tabular}{|c|c|c|c|c|c|c|c|}
\hline $\begin{array}{l}\text { Patient } \\
\text { Number }\end{array}$ & $\begin{array}{c}\text { Age } \\
\text { (years) }\end{array}$ & Sex & $\begin{array}{l}\text { Type of } \\
\text { Lesion }\end{array}$ & $\begin{array}{l}\text { Site \& } \\
\text { Location }\end{array}$ & $\begin{array}{l}\text { Number of } \\
\text { Lesions }\end{array}$ & $\begin{array}{l}\text { Size of } \\
\text { Lesions }\end{array}$ & *Prior Therapy \\
\hline 1 & 39 & $\mathrm{~F}$ & $\begin{array}{c}\text { Intransit } \\
\text { Metastases }\end{array}$ & $\begin{array}{l}\text { Skin and subcutaneous } \\
\text { Tissue: Thigh }\end{array}$ & 10 & 3-10 mm & Multiple excisions \\
\hline 2 & 79 & M & Intransit metastases & Scalp & Too many & $2-3 \mathrm{~mm}$ & BCG \\
\hline 3 & 52 & $\mathrm{~F}$ & Intransit metastases & Subcutaneous tissue: Leg\& Thigh & 13 & $5-10 \mathrm{~mm}$ & $\begin{array}{l}\text { Multiple excisions, HILP, } \\
\text { LI, BCG }\end{array}$ \\
\hline 4 & 44 & M & Intransit metastases & Subcutaneous tissue: Thigh & 3 & $5-10 \mathrm{~mm}$ & $\begin{array}{c}\text { Multiple excisions, HILPx2 } \\
\text { \& RT }\end{array}$ \\
\hline 5 & 74 & M & $\begin{array}{l}\text { Intransit } \\
\text { metastases }\end{array}$ & $\begin{array}{l}\text { Skin and subcutaneous tissue: } \\
\text { Shoulder }\end{array}$ & $\begin{array}{l}\text { Coalesced } \\
\text { And scaly }\end{array}$ & $\begin{array}{l}\text { Large } \\
>30 \mathrm{~mm}\end{array}$ & Multiple excisions and BCG \\
\hline 6 & 51 & M & Intransit metastases & $\begin{array}{l}\text { Skin and subcutaneous tissue: } \\
\text { Neck }\end{array}$ & $\begin{array}{l}\text { Coalesced forming soft } \\
\text { tissue masses }\end{array}$ & $\begin{array}{l}\text { Large } \\
>50 \mathrm{~mm}\end{array}$ & Multiple excision and BCG \\
\hline 7 & 67 & M & Intransit metastases & Scalp & $\begin{array}{l}\text { Coalesced forming soft } \\
\text { tissue masses }\end{array}$ & $\begin{array}{l}\text { Large } \\
>50 \mathrm{~mm}\end{array}$ & Multiple excisions \& RT \\
\hline 8 & 70 & M & Primary \& satellite & Skin: forearm & 2 & $2-3 \mathrm{~mm}$ & None \\
\hline 9 & 63 & $\mathrm{~F}$ & Distant metastases & $\begin{array}{l}\text { Subcutaneous tissue: } \\
\text { Supraclavicular }\end{array}$ & 2 & $\begin{array}{l}5-7 \\
\mathrm{~mm}\end{array}$ & Systemic \\
\hline 10 & 50 & $\mathrm{~F}$ & Distant metastases & Subcutaneous tissue: axilla & 3 & $\begin{array}{l}5-10 \\
\mathrm{~mm}\end{array}$ & None \\
\hline
\end{tabular}

*Prior therapy for the treated lesions, BCG: bacillus Calmette Guerin, HILP: hyperthermic isolated limb perfusion, LI: limb infusion, RT: radiation therapy

Table 1: Demographics of the Study Patients. 


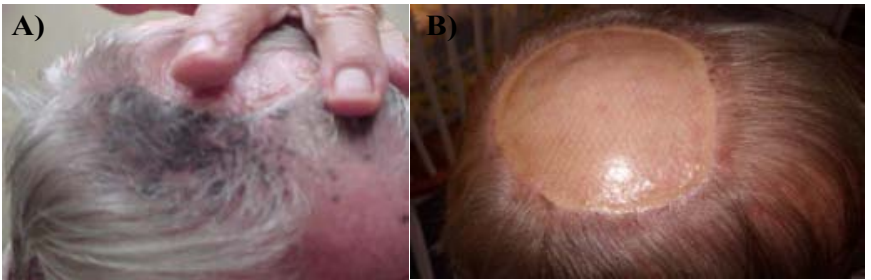

Figure 1: (A) On the left, a close-up photograph of a section of the scalp of patient \# 2 prior to intralesional therapy showing the massive in transit metastases next to the skin graft, and $(B)$ on the right, a photograph of the whole scalp of the same patient after receiving GM-CSF intralesional therapy. Note the complete clinical response which was confirmed pathologically. This patient is alive free of disease for 44 months to date.

disease, there was not enough time for repeated weekly intralesional injections of either cytokine. Therefore, the patient received a single short course of intralesional $500 \mu \mathrm{g}$ GM-CSF on day \# 1, followed by IL-2 at 11 million IU/day on days \# 2 and 3 at the primary and satellite sites. One week later, the standard surgical procedure was carried out that included wide excision of the skin, subcutaneous tissue and the underlying fascia with $2 \mathrm{~cm}$ margin from the primary site and the satellite and a total axillary LN dissection. All the resected tissues were examined pathologically.

Two other patients (\# 9, 10) had distant metastases with some palpable tumors in the subcutaneous tissue amenable to transdermal injections. One had 2 subcutaneous lesions each measuring about $1 \mathrm{~cm}$ located at both supraclavicular areas with metastases to soft tissue in the back and left iliac lymph node. The second patient had two subdermal tumor nodules in the right anterior axillary fold and lung metastases.

\section{Results}

This approach was well tolerated as there was no clinical, hematological, renal or hepatic toxicity or any elevation in LDH. However, two patients complained of bone pain immediately after GMCSF administration that lasted for about one hour. In addition, there was moderate skin reaction to GM-CSF administration when injected in the dermal lesions that lasted for 24 hours. There were no significant changes in the total WBC or their cell differentiation. None of the eight patients without distant metastases developed any metastases during the observation period.

Three of the four patients (\#1-4) with multiple small in transit metastases who initially received GM-CSF had complete response within four weeks of intraregional therapy. One failed and was successfully treated with intralesional IL-2, table 2. Each of these four patients had one or more tumor sites re-biopsied at 6-8 weeks after cessation of the therapy and no tumor or mononuclear cell infiltrate were identified histopathologically. While patient \# 2 (Figure 1B) had no recurrence, each of the other three developed single new intransit metastases in none of the treated sites at 12-22 months and were managed by local excisions only. All four patients are alive free of disease for 31-48 months to date. On the other hand, the three patients with large sclerotic lesions failed to show any tumor response to either agent and were taken off the study and treated with other therapeutic modalities. In addition, the two patients who had previously failed systemic adjuvant therapy with GM-CSF and IL-2; one responded to intralesional GM-CSF (\#1) and the other responded to intralesional IL-2 (\#3), table 2. As with regard to the two patients with distant metastases $(\# 9,10)$, the one with soft tissues metastases to the back and left iliac LN had CR to all lesions for six months then recurred in both adrenal glands. The second patient had CR to GM-CSF at the injection sites, but the lung metastases continued to progress. Their responses at the injection sites were confirmed histopathologically. The resected tissues of patient \# 8who received preoperative single short course of GM-CSF followed by IL-2 at the primary site and the satellite lesion revealed complete tumor necrosis at the primary site (Figure 2) and the satellite lesion with massive pigmented histiocytes at both skin sites and in several regional LNs. However, the one enlarged LN that measured $3 \mathrm{~cm}$ contained metastases. Therefore, because of this pathological discovery, immunohistochemistry (IHC) studies were performed retrospectively on the resected tissues from formalin fixed paraffin embedded blocks. The tissue from the primary site and satellite after intralesional therapy was compared to the tissues from the biopsy sites of the same patient, i.e., before therapy, and the LN tissue after therapy, were compared to LN of untreated patient. The results revealed overexpression of CD3+, CD4+, CD8+ and CD83+ cells at the primary site, the satellite and in some regional LNs after intralesional therapy. This patient is alive free of disease-for over 36 months to date.

\section{Discussion}

Weekly intralesional therapy with GM-CSF or IL-2 was well

\begin{tabular}{|c|c|c|c|c|c|}
\hline $\begin{array}{l}\text { Patient } \\
\text { Number }\end{array}$ & $\begin{array}{c}\text { Agent } \\
\text { (cytokine) }\end{array}$ & $\begin{array}{l}\text { Duration } \\
\text { Of therapy } \\
\text { (weeks) }\end{array}$ & $\begin{array}{l}\text { Tumor } \\
\text { response }\end{array}$ & $\begin{array}{c}\text { Disease-free } \\
\text { Period } \\
\text { (months) }\end{array}$ & $\begin{array}{l}\text { Overall } \\
\text { Survival } \\
\text { Up to date } \\
\text { (months) }\end{array}$ \\
\hline 1 & GM-CSF & 4 & CR & 22 & 48 \\
\hline 2 & GM-CSF & 4 & CR & 44 & 44 \\
\hline 3 & $\begin{array}{c}\text { GM-CSF } \\
\text { IL-2 }\end{array}$ & $\begin{array}{l}4 \\
4\end{array}$ & $\begin{array}{l}\text { None } \\
\text { CR }\end{array}$ & $\begin{array}{c}- \\
12\end{array}$ & - \\
\hline 4 & GM-CSF & 3 & CR & 12 & 31 \\
\hline 5 & $\begin{array}{c}\text { GM-CSF } \\
\text { IL-2 }\end{array}$ & $\begin{array}{l}4 \\
4\end{array}$ & $\begin{array}{l}\text { None } \\
\text { None }\end{array}$ & $\begin{array}{l}\text { None } \\
\text { None }\end{array}$ & $\mathrm{N} / \mathrm{A}$ \\
\hline 6 & $\begin{array}{c}\text { GM-CSF } \\
\text { IL-2 }\end{array}$ & $\begin{array}{l}4 \\
4\end{array}$ & $\begin{array}{l}\text { None } \\
\text { None }\end{array}$ & $\begin{array}{l}\text { None } \\
\text { None }\end{array}$ & N/A \\
\hline 7 & $\begin{array}{c}\text { GM-CSF } \\
\text { IL-2 }\end{array}$ & $\begin{array}{l}4 \\
4\end{array}$ & $\begin{array}{l}\text { None } \\
\text { None }\end{array}$ & $\begin{array}{l}\text { None } \\
\text { None }\end{array}$ & $\mathrm{N} / \mathrm{A}$ \\
\hline 8 & $\begin{array}{c}\text { GM-CSF \& } \\
\text { IL-2 }\end{array}$ & 1 & CR & 36 & 36 \\
\hline 9 & GM-CSF & 6 & CR & 6 & $\mathrm{~N} / \mathrm{A}$ \\
\hline 10 & GM-CSF & 6 & $\begin{array}{c}\text { CR at } \\
\text { injection sites, } \\
\text { progression } \\
\text { in lung } \\
\text { metastases }\end{array}$ & None & $N / A$ \\
\hline
\end{tabular}

$\mathrm{CR}=$ complete tumor response

$\mathrm{N} / \mathrm{A}=$ not applicable as the patient received other therapy

Table 2: Intralesional Therapy \& Summary of the Results.
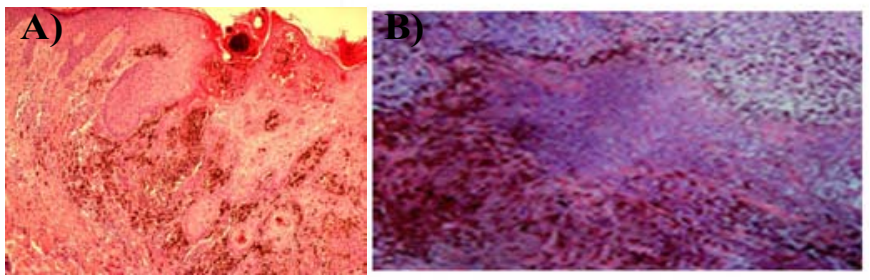

Figure 2: The histopathology of the primary site of the cutaneous melanoma of patient \# 8: (A) Prior to intralesional biotherapy from the biopsy site, and (B) One week after intralesional therapy from the resected tissue of the same patient. Note the massive tumor necrosis and the abundant pigmented histiocytes. (H\&E X400). 
tolerated and was as effective as the more frequent administration of either agent. The bone pain after GM-CSF administration could be due to bone marrow stimulation. Complete responses were seen with GMCSF therapy in satellitosis and in multiple small intransit metastases regardless to their numbers and location. Failure to GM-CSF therapy was successfully rescued by intralesional IL-2 as seen in patient \#3. This suggested that the consecutive administration of both cytokines could be more effective than the use of a single agent. Based on this observation, patient \# 8 who had small size primary invasive melanoma and a satellite lesion received preoperative sequential intralesional GMCSF and IL-2. This resulted in massive tumor necrosis at the injection sites and extensive pigmented histiocytes at the primary lesion, the satellite and some of the regional LNs. This suggested a potent immune response. Therefore, it seemed that preoperative administration of both cytokines at the primary site of high risk cutaneous melanoma patients could utilize in vivo the primary tumor as a source for tumor-specific antigens to induce a strong antitumor immune response, specific to the patient. The presence of pigmented histiocytes in some of the regional LNs could suggest that the cytokines and their induced immune cells had been taken up by the lymphatics, and that early metastases to some regional LNs could have been eliminated immunologically. In addition, it was of interest to note the response to intralesional therapy in the two patients who developed intransit metastases after failing the initial postoperative systemic adjuvant therapy to relatively higher doses of both GM-CSF and IL-2.

On the other hand, large sclerotic skin lesions failed to respond to either cytokine. This could be due to inability to infiltrate the lesions or the patient being immune compromised. It should be noted that none of these patients (\#1-8) developed systemic metastases during the study and follow up period. The response seen in the two patients with systemic disease could suggest a role for intralesional therapy in patients with limited distant metastases, if the lesion can be reached transdermal under sonogram or CT control. In addition, recurrent intransit metastases occurred in three patients who were previously treated. While local surgical excisions seemed to be effective, theoretically repeated intralesional therapy may prove to be more beneficial as it could process new tumor cell clones which might have been the result of the mutation of residual tumor cells. However, a combined approach of intralesional therapy and local excision may prove to be more effective.

In the meantime, it has been shown that patients with resected metastatic melanoma whose tumors had melanoma-specific tumor infiltrating lymphocytes (TILs) had statistically better survival compared to those who had melanoma-specific cells in their peripheral blood, and at no time these immune cells were detected in the tumor and in the peripheral blood at the same time in any of the patients [9]. In our approach, intralesional administration of GM-CSF can activate preexisting autologous dendritic cells or induced such cells, which are very efficient antigen processing cells (APCs) capable of processing the tumor antigens and present their processed antigens (cross-talk) to $\mathrm{T}$ lymphocytes. In addition, IL-2 administration can induce $\mathrm{T}$ lymphocytes or stimulate preexisting TILs at the tumor sites. Azimi et al. [10] have shown that the amount of TIL at the primary site seemed to play a major role in the patient prognosis and the status of sentinel LNs. The intralesional administration of GM-CSF and IL-2 can activate or induce TIL in patient own tumor. This could explain, at least in part, the potential mechanism of action to intralesional therapy of both cytokines. It has also been reported that intradermal administration of GM-CSF near the biopsy site of primary melanoma did increase the number and activation of dendritic cells and tumor-specific CD8+ cells in sentinel LNs in patients with early stage melanoma $[11,12]$ This could indicate that intradermal injection of a cytokine at or near a biopsy site of a primary melanoma did utilize the lymphatic route to deliver the immune response to the regional LNs. This was further confirmed in this study by the presence of massive histiocytosis and various immune cells in the regional lymph nodes. Some of our patients with in transit metastases had regional lymphadenectomy at the time of the initial diagnosis, but this did not affect the results as new lymphatic channels could have carried out the immune response.

Furthermore, the route of antigen or vaccine administration can be a critical variable in determining the outcome of an immune response. In an animal model, when a vaccine with naked antigen-encoding RNA was administered in the skin, subcutaneous tissue or near a lymph node, no significant immune response was noted. However, when this vaccine was given in a lymph node, it elicited potent prophylactic and therapeutic antitumor immunity [13]. Therefore, the lymphatic route of administration of a vaccine or its immune cells, which has never been used in human, can be beneficial. In addition, some of the treated lesion sites which were re-biopsied 6-8 weeks after intralesional therapy revealed no evidence of residual tumor or immune cells. This could indicate that such time-period was long enough for a wash-out of the effect of therapy. On the other hand, the patient who presented preoperatively with a primary lesion, a satellite and metastasis to the regional LN who was treated by both cytokines just one week prior to the surgery, gave us an opportunity for early evaluation of the local and regional immune effect one week after therapy.

It has also been shown that the induction of high levels of immune cells in the peripheral blood of melanoma patients did not correlate to tumor response in both metastatic stages and as adjuvant therapy $[14,15]$. Therefore, there was no need to monitor the peripheral blood in our patients, especially when using low doses of GM-CSF and IL-2 for a short period of time. It should be noted that all the immune response seemed to be transmitted via the lymphatics without any effect on the peripheral blood WBC or their cell differentiation.

The IHC studies were not performed on the sites of in transit metastases which were biopsied 6-8 weeks after cessation of therapy because of the absence of tumor and mono-nucleated cells. However, when performed on the resected tissues of patient \# 8, one week after intralesional therapy, showed complete tumor necrosis and massive histiocytosis with an intense immune response characterized by overexpression of $\mathrm{CD} 3+, \mathrm{CD} 4+, \mathrm{CD} 8+$ and $\mathrm{CD} 83+$ cells locally at the injection sites and regionally at the LNs. While CD83+ cells could be detected temporarily in $\mathrm{T}$ and $\mathrm{B}$ cells, they are expressed permanently in mature and functional dendritic cells [16].

Sequential administration of GM-CSF and IL-2 had never been reported before in the management of satellitosis or intransit metastases, or preoperatively as adjuvant therapy. This is the first report of utilizing the primary site of cutaneous melanoma as a source for melanoma antigens specific to the patient to induce strong antitumor immune response. Melanoma is a very heterogeneous tumor, and intralesional therapy utilizes the patient own tumor as a source for tumor-specific antigens. The induction or activation of autologous dendritic cells and $\mathrm{T}$ lymphocytes by intralesional therapy, in the presence of melanoma cells, can result in a strong immune response specific to the patient. The long term survival of the responders could indicate systemic impact of the therapy without an apparent effect on the peripheral blood. 
Citation: Elias EG, Sharma BK (2013) Targeting Melanoma Sites in Vivo can Induce Complete Tumor Ablation and Prolong Patient Survival: An Exploratory Study. J Cancer Sci Ther 5: 244-248. doi:10.4172/1948-5956.1000212

\section{Conclusion}

In conclusion, it seems that intralesional therapy with GM-CSF/IL-2 can be effective in primary as well as in some metastatic melanoma. In addition, preoperative intralesional administration of both cytokines at the primary site can induce a strong antitumor autoimmune response in vivo, specific to the patient, as an adjuvant immunotherapy. These two cytokines can be administered with autologous vaccines, but never with allogenic material as it can result in immune deviation or tolerance. These observations open new aspects for clinical trials.

\section{References}

1. Vaquerano JE, Cadbury P, Treseler P, Sagebiel R, Leong SP (1999) Regression of in-transit melanoma of the scalp with intralesional recombinant human granulocyte-macrophage colony-stimulating factor. Arch Dermatol 135 1276-1277.

2. Hoeller C, Jansen B, Heere-Ress E, Pustelnik T, Mossbacher U, et al. (2001) Perilesional injection of $\mathrm{r}-\mathrm{GM}-\mathrm{CSF}$ in patients with cutaneous melanoma metastases. J Invest Dermatol 117: 371-374.

3. Radny P, Caroli UM, Bauer J, Paul T, Schlegel C, et al. (2003) Phase II trial of intralesional therapy with interleukin-2 in soft-tissue melanoma metastases. $\mathrm{Br}$ J Cancer 89: 1620-1626.

4. Dehesa LA, Vilar-Alejo J, Valerón-Almazán P, Carretero G (2009) [Experience in the treatment of cutaneous in-transit melanoma metastases and satellitosis with intralesional interleukin-2]. Actas Dermosifiliogr 100: 571-585.

5. Weide B, Derhovanessian E, Pflugfelder A, Eigentler TK, Radny P, et al. (2010) High response rate after intratumoral treatment with interleukin-2: results from a phase 2 study in 51 patients with metastasized melanoma. Cancer 116: 4139-4146.

6. Si Z, Hersey P, Coates AS (1996) Clinical responses and lymphoid infiltrates in metastatic melanoma following treatment with intralesional GM-CSF. Melanoma Res 6: 247-255

7. Nasi ML, Lieberman P, Busam KJ, Perito V, Panageas KS, et al. (1999) Intradermal injection of granulocyte-macrophage colony- stimulating (GM-CSF) in patients with metastatic melanoma recruits dendritic cells. Cytokines Cell Mol Ther 5: 139-144

8. Medzhitov R, Janeway C Jr (2000) Innate immune recognition: mechanisms and pathways. Immunol Rev 173: 89-97.

9. Haanen JB, Baars A, Gomez R, Weder P, Smits M, et al. (2006) Melanomaspecific tumor-infiltrating lymphocytes but not circulating melanoma-specific $\mathrm{T}$ cells may predict survival in resected advanced-stage melanoma patients. Cancer Immunol Immunother 55: 451-458.

10. Azimi F, Scolyer RA, Rumcheva P, Moncrieff M, Murali R, et al. (2012) Tumorinfiltrating lymphocyte grade is an independent predictor of sentinel lymph node status and survival in patients with cutaneous melanoma. J Clin Oncol 30: $2678-2683$

11. Vuylsteke RJ, Molenkamp BG, Gietema HA van Leeuwen PA, Wijnands PG, et al. (2004) Local administration of granulocyte/macrophage colony-stimulating factor increases the number and activation state of dendritic cells in sentine lymph node of early-stage melanoma. Cancer Res 64: 8456-8460.

12. Vuylsteke RJ, Molenkamp BG, van Leeuwen PA, Meijer S, Wijnands PG, et al. (2006) Tumor-specific CD8+ T cell reactivity in the sentinel lymph node of GM-CSF-treated stage I melanoma patients is associated with high myeloid dendritic cell content. Clin Cancer Res 12: 2826-2833.

13. Kreiter S, Selmi A, Diken M, Koslowski M, Britten CM, et al. (2010) Intranoda vaccination with naked antigen-encoding RNA elicits potent prophylactic and therapeutic antitumoral immunity. Cancer Res 70: 9031-9040

14. Smith II JW, Kurt RA, Baher AG, Denman S, Justice L, et al. (2003) Immune effects of escalating doses of granulocyte-macrophage colony-stimulating factor added to a fixed, low-dose, inpatient interleukin-2 regimen: a randomized phase I trial in patients with metastatic melanoma and renal cell carcinoma. $J$ Immunother 26: 130-138.

15. Rosenberg SA, Sherry RM, Morton KE, Scharfman WJ, Yang JC, et al. (2005) Tumor progression can occur despite the induction of very high levels of self/ tumor antigen-specific CD8+ T cells in patients with melanoma. J Immunol 175 6169-6176.

16. Cao W, Lee SH, Lu J (2005) CD83 is preformed inside monocytes, macrophages and dendritic cells, but it is only stably expressed on activated dendritic cells. Biochem J 385: 85-93. 